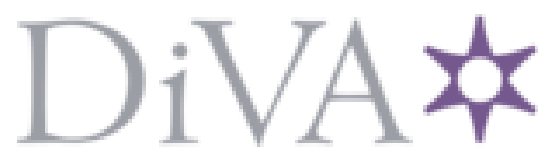

http://www.diva-portal.org

This is the published version of a paper presented at 9th International Conference on the European Energy Market, EEM 12; Florence;10 May 2012 through 12 May 2012.

Citation for the original published paper:

Huang, Y., Alvehag, K., Söder, L. (2012)

Regulation impact on distribution systems with distributed generation.

In: 9th International Conference on the European Energy Market, EEM 12 (pp. 6254721 -). IEEE

International Conference on the European Energy Market

http://dx.doi.org/10.1109/EEM.2012.6254721

N.B. When citing this work, cite the original published paper.

Permanent link to this version:

http://urn.kb.se/resolve?urn=urn:nbn:se:kth:diva-93313 


\title{
Regulation impact on distribution systems with distributed generation
}

\author{
Yalin Huang, Karin Alvehag, and Lennart Söder
}

\begin{abstract}
Distribution system operators (DSOs) are facing new challenges when more distributed generation (DG) is connected to the network. In this new operating environment the DSO has to be able to plan an efficient network topology, which consists of reinforcement and extensions. In addition, the DSO has to finance the investment from tariffs. The methods to solve network planning problems are reviewed in this paper. The studied network planning problem is the case when the DSO has no influence on the location of DG due to the unbundling between DSOs and production. Furthermore, the regulation for how the DSOs are allowed to design the tariffs in systems with DG vary between countries, a comparison of how the DSOs design their tariffs under different regulations is presented. This paper ends with a case study on methods that Swedish DSOs use to plan the networks when considering the uncertainties caused by wind power and the regulation impact on distribution network planning and network tariffs in Sweden.
\end{abstract}

Index Terms-distributed generation, network planning, network tariff, regulation.

\section{INTRODUCTION}

D ISTRIBUTION system operators (DSOs) are facing new challenges when more distributed energy resource (DER) is connected to the grid. DER consists of distributed generation (DG), distributed storage and active demand load at the distribution level. The definition of the term DG has been analyzed in detail in [1]. In this paper, DG is considered as generation connected to distribution networks. Both positive and negative impacts for integrating DG into electric power system are analyzed in [2] [3] and [4]. This paper focuses on two of the new challenges for the DSO due to DG: network planning methods that consider the impact of DG and network tariff design for DG.

Distribution networks are traditionally not designed to accommodate generation, hence, increasing DG penetration is causing profound changes in planning, operation and maintenance of distribution networks [5]. In this new operation environment regulation should send out incentives for the DSOs to plan an efficient network which consists of reinforcement and extension to accommodate the increasing levels of DG. Both the positive and negative effects of DG need to be considered in the network planning. An inefficient network planning can lead to high costs that are paid by the network users, therefore, DSOs are required to design a more efficient and transparent

Y. Huang is with the School of Electrical Engineering, Royal Institute of Technology, Stockholm, Sweden,e-mail: yalin. huangeee.kth.se

$\mathrm{K}$. Alvehag is with the School of Electrical Engineering, Royal Institute of Technology, Stockholm, Sweden

L. Söder is with the School of Electrical Engineering, Royal Institute of Technology, Stockholm, Sweden network tariff structure to fairly allocate benefits and costs by regulation. Moreover, regulation can give guidance to DSOs on how to design a cost reflective network tariff.

The optimal location and sizing of DER is essential to maximize the benefits of DER [6]. Many researchers focus on planning DG (some authors also include other DER options), which is to optimize DG type, size and/or location in order to achieve a set of objectives subject to a set of constraints. A state-of-art review of the reported works on planning DG (or DER) can be found in [7]. However, DSOs have no direct influence on DG installation in many European countries where electricity industries are highly unbundled. Moreover, DSOs are obliged to connect DG into the grid by regulation. This is the case in countries such as Sweden and Germany. Therefore the task of the DSO is how to connect DG to the system in an optimal way instead of deciding the optimal size and the location of DG [8]. Only few researchers formulate the problem in a way that the location of DG is not decided by the DSO [9]. Even though the DSO knows the planned location of DG there are still uncertainties in the network planning process since not all planned DG projects will be carried out.

For DSOs network planning methods for DG and network tariff design for DG are closely related. On one hand, how and when the DSOs choose to expand and reinforce the network are closely related to DSOs' costs. On the other hand, remuneration for their services are closely related to how network tariffs are designed. In some deregulated electric power systems, the DSOs can decide how to allocate their costs to customers. The regulation for how the DSOs are allowed to design network tariffs in systems with DG varies between countries. Network tariffs for DG also can be designed differently from DSO to DSO even in the same country. From an operational point of view, to achieve network efficiency considering increasing DG, it is beneficial that network tariffs reflect the value of DG to the network [10], [11].

One contribution of this paper is to analyze regulation impact on network planning methods and network tariff designs in unbundled electricity network. By considering both aspects, the DSOs gain a comprehensive understanding of the effects due to DG. The second contribution of this paper is a case study of Swedish DSOs. The case study investigates network planning methods and network tariff structure for DSOs who can not decide the location of DG.

This paper is organized as follows: In Section II optimization methods applied in distribution network planning under uncertainties are reviewed. In Section III tariff designs under different network regulations are compared. In Section 
IV a case study of Sweden is presented. The case study shows preliminary findings from a survey for Swedish DSOs regarding planning DG connection and designing network tariffs for DG. Finally, the conclusions are drawn in Section V.

\section{NETWORK PLANNING AS AN OPTIMIZATION CHALLENGE}

One aim of distribution network planning is to maximize the profit for the DSO considering the network regulation. To determine the optimal network reinforcement and expansion plan one can solve it as an optimization problem. Traditional network planning methods and tools are unable to deal with a high uncertain future when applied to distribution system with DG [12]. As more DG is integrated to the grid, more uncertainties enter the planning process for the DSO. Uncertain information is always a challenge in network planning [13], especially in those countries where electricity networks are unbundled from generation, DSOs will encounter uncertainties such as the timing of DG connection, the location and production of DG.

According to [14] one methodology consists of three phases can be used by the DSO to find the optimal network planning for possible scenarios with different levels of DG and growing load demand. These three different phases are illustrated in Fig 1. Firstly, define possible scenarios with probabilities of occurrence. Secondly, generate network planning alternatives for each scenario. The network planning problem will turn into a multi-criteria optimization problem. Thirdly, based on one's decision criteria choose a network planning solution.

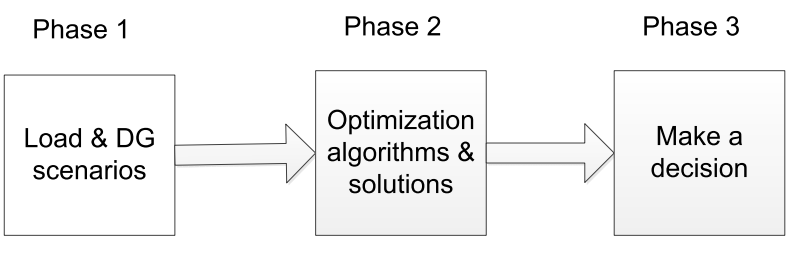

Fig. 1. Three phases of network expansion planning

\section{A. Phase 1: Possible scenarios of the future}

Note that to assign the probabilities to each DG connection is an important aspect of network planning because DG location and production are unknown for DSOs. Modeling the probabilities associated to location and production of DG has a significant influence on the final decision. There are several models for uncertainties, but few have been found to model the DG scenarios. In [15] uncertain variables are produced by Monte Carlo analysis. Since the DSO will receive the application for connection from DG developers, the DSO can predict probable generation and load for the coming period. Most studies are based on that the probability distribution of load evolution is assumed to be known for each node in the system [9] [15].

\section{B. Phase 2: Optimization algorithms applied to distribution network planning}

Network planning with DG can be formulated from two perspectives: the DG installers' perspective who are interested in generation planning and the DSOs' perspective who are performing network planning under uncertainties caused by DG [12]. This paper focuses on the perspective of DSOs.

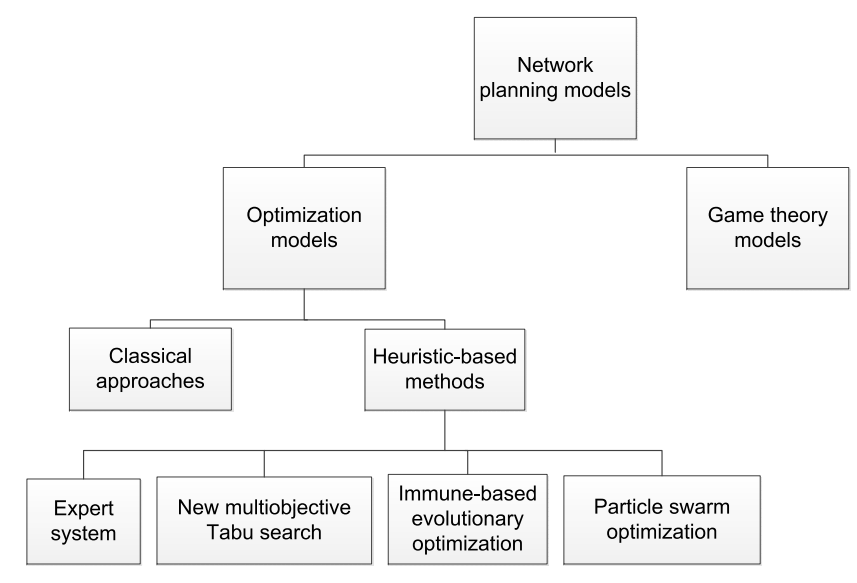

Fig. 2. Network planning methods

As the optimization problem for network planning is combinatorial, non-linear with mixed integer variables and constrained, heuristic-based methods are more convenient than classical approaches according to [14] [18]. In this section four heuristic-based optimization methods applied on network planning are reviewed. The four methods are: expert system, multi-objective Tabu search, artificial immune system and particle swarm optimization (Fig 2). A general comparison of different methods is presented in Table I. A novel way to model the network planning problem -game theory- is also presented. Similar difficulties of network planning also exist on transmission level. Reviewed methods in this paper have also been applied on transmission level, for example in [19] [20] [21] [22] and [23]. Most of the reviewed methods have not yet been applied to systems with DG, however the uncertainty in load growth is considered in every model. The reviewed methods are the most advanced algorithms applied in network planning so far. The next step is to develop them to be able to consider DG.

The expert system method proposed in [16] for distribution network does not require prior knowledge of network planning alternatives, because selecting location of a substation, the optimal feeder configuration and the optimal sizes of branch conductors is automatic. The objective function in [16] is to minimize the total cost of capital investment and real power losses. Three different algorithms namely optimum location of substation, optimal feeder path and optimal branch conductor selection have been developed for the proposed expert system planning method. Although DG integration is not considered, load growth is incorporated in the algorithm to compute future replacement/reinforcement of line due to inadequate size of conductors.

A new multi-objective Tabu search (NMTS) algorithm is proposed in [17]. The work in [17] is a development of the 
TABLE I

A GENERAL COMPARISON OF DIFFERENT METHODS

\begin{tabular}{|c|c|c|c|}
\hline Heuristic algorithms & Objectives & Variables & Main advantages \\
\hline $\begin{array}{l}\text { Expert system (ES) presented } \\
\text { in [16] }\end{array}$ & Minimization of total costs & $\begin{array}{l}\text { Location of substation } \\
\text { Feeder configuration } \\
\text { Size of branch conductor }\end{array}$ & $\begin{array}{l}\text { No required prior knowledge of network } \\
\text { planning alternatives }\end{array}$ \\
\hline $\begin{array}{l}\text { Multi-objective Tabu search } \\
\text { (NMTS) presented in [17] }\end{array}$ & $\begin{array}{l}\text { Minimization of total costs } \\
\text { Maximization of reliability } \\
\text { level } \\
\text { Minimization the risk of } \\
\text { networks }\end{array}$ & $\begin{array}{l}\text { Size and location of reserve } \\
\text { feeders }\end{array}$ & $\begin{array}{l}\text { Multi-objective non-dominated solutions to all } \\
\text { objective functions obtained } \\
\text { Avoidance of unwanted movements } \\
\text { Diversification of the search to obtain a proper } \\
\text { distribution of solutions }\end{array}$ \\
\hline $\begin{array}{l}\text { Immune-based evolutionary } \\
\text { optimization presented in [15] }\end{array}$ & $\begin{array}{l}\text { A monetary representative of } \\
\text { minimization of energy losses } \\
\text { and minimization of new } \\
\text { investment }\end{array}$ & $\begin{array}{l}\text { Possible connections between } \\
\text { two nodes }\end{array}$ & $\begin{array}{l}\text { Consideration of the uncertainties in the } \\
\text { evolution of load and energy tax in each node } \\
\text { in a time horizon }\end{array}$ \\
\hline $\begin{array}{l}\text { Particle swarm optimization } \\
\text { (PSO) presented in [18] }\end{array}$ & $\begin{array}{l}\text { Minimization of total costs of } \\
\text { installation and energy loss } \\
\text { Maximization of network } \\
\text { reliability }\end{array}$ & $\begin{array}{l}\text { Conductor replacement } \\
\text { Substation location } \\
\text { Branch conductor size }\end{array}$ & $\begin{array}{l}\text { Less computational bookkeeping and fewer } \\
\text { lines of implementation codes }\end{array}$ \\
\hline
\end{tabular}

method presented in [24]. Reference [24] applies a multiobjective fuzzy model for distribution network planning. The objective functions are: the minimization of total costs, the maximization of reliability level and minimization the network risks. Risk here represents the possibility of surpassing the power capacity limits of the substations and feeders. The variables are size and location of reserve feeders. This model considers a fuzzy explicit representation of the uncertainties associated with the future demand as well as a fuzzy representation of the uncertainties associated with the expansion cost of the distribution network. This NMTS algorithm determines the optimal solution for maximizing the network reliability at the lowest cost for a given level of risk. The main advantages of this search algorithm as stated in [17] are: (i) it obtains multi-objective non-dominated solutions to the three objective functions, (ii) it intensifies the search by ranking lists of the best network nodes of the distribution and stores visited network nodes avoiding unwanted movements, (iii) it diversifies the search to obtain a proper distribution of solutions.

An immune-based evolutionary optimization algorithm proposed in [15] considers the uncertainties in the evolution of load and energy tax in each node in a time horizon. Artificial immune systems (AIS) is applied as computational techniques, which deliver not only a single solution at the end of the optimization procedure, but also an entire set of suboptimal solutions [25]. The objective function in [15] is a monetary representative of minimization of energy losses and minimization of new investment. The variables represent possible connection between two nodes in the network. An important feature of this algorithm is that it finds the optimal topology first and then the optimal conductor set for that topology.

The particle swarm optimization (PSO) is applied to solve the network planning problem on distribution level [18] and on transmission level [26]. Some applications have reported that PSO performs similar as or better than other evolutionary optimization algorithms [18]. The most attractive feature of PSO according to [18] is that it requires less computational bookkeeping and fewer lines of implementation codes [18].
PSO is based on the social behavior of a bird flock or a fish school, each object in the swarm updates their position and velocity in a continuous and fast manner. A population of initial search points are called particles. Each particle is assigned a position vector containing an $\mathrm{n}$-dimensional information which is updated by velocity in successive iterations. The velocity vector of a node is updated using its own previous best value by following the best particle from its group. The initial position and velocity are chosen randomly. Three improved versions of PSO are reviewed in [18]. The two planning objectives are: (i) minimization of total cost of installation and energy loss; (ii) maximization of network reliability. The variables are conductor replacement, substation location and branch conductor size. The network reliability is expressed in terms of energy not served which is a function of failure rate and repair duration of each feeder branch. In [18] a mono-objective PSO-based planning is used to optimize the two objectives separately. At the same time, a multi-objective PSO-based planning is used to optimize the two conflicting objectives simultaneously. Both algorithms are applied for static as well as dynamic planning of distribution networks. It concludes that the multi-objective optimization is more realistic as it optimizes the conflicting objectives simultaneously using the Pareto-optimality principle. This results in that the DSO is provided with more choices, the Pareto-approximation set, from which the DSO can select one final design.

One novel way to model this multi-objective optimization problem is to apply game theory. The planning process is modeled as a multi-stage non-zerosum game with cooperative rational players. The solution is a total optimum for all the players. The different criteria in the optimization problem such as reliability, economic efficiency, operating performance and technical feasibility are suggested by [9] and [27] to be represented as individual game players. As the benefits of the game players are related sometimes, some criteria in network planning process are naturally contradictory or consistent. For example, minimize the cost and maximize the DG penetration level can be contradictory. Thus, the game theory model can be a good representative of the network planning problem. If 
$n$ alternatives of the network expansion or reinforcement are suggested, either choose one alternative or not choose this one results in $n^{2}$ strategy-combinations of the game. Equilibrium in game theory means to search for a solution that is a Parato optimum and satisfies the requirements of all players [27]. The impact of DG on network planning is analyzed in [9] and [27]. The advantages of this approach as stated in [9] are (i) the criteria are not fixed boundary value anymore but variable criteria which can be optimized; (ii) dependencies and interactions of criteria during the process become visible; (iii) the expansion strategies can also be at different time.

\section{Phase 3: Decision making}

Once several optimal and suboptimal solutions for each scenario are found, DSOs select the most satisfactory plan to implement. Due to some conflicting objectives, infeasibility rate can be used as the first filter to analyze the results [15]. After applying the filter a group of non dominated solutions will be left. The DSOs then select the final solution based on their experience or according to a decision making method.

Two basic approaches that can be used to make decision are probability choice (PC) and risk analysis (RA) [14]. The PC approach solution is based on the minimization of expected cost, so this solution is the best on average of the futures, but if that occurred in the future is far from the average, there will be a high regret. Regret here is in terms of additional cost suffered for having chosen a network alternative different from the optimal one [14]. For example in [24], a max-min approach has been used to select the final planning solution. Later in [17] a min-max approach is preferred. In [15] a sensitivity analysis is conducted to the candidate-solution set under a set of load levels. The final solution is chosen as the one that minimizes the cost under certain constraints of feasibility and reliability.

The RA approach solution is based on the minimal regret that the decision maker would feel. Minimal risk criterion is suitable for cases with active intelligent opponent, who intentionally would choose the worst for the opponent. However, this situation is not typical for the network planning task [13]. A mix of the above two approaches named PC+RA is applied in [28], [29], [30]. The mixed approach mainly overcomes the probability assignment problem which is the first step in network planning modeling. A concept named stability areas (SA), which build from pure PC and RA results, is proposed in [31]. The results correspond to the combinations of scenario probabilities for which a network alternative is constant, irrespective of the chosen approach [14]. In absence of any information about which scenario is more reasonable, the planner can choose the alternative which corresponds to the largest stability area.

\section{NETWORK TARIFF DESIGN}

There are mainly two different kinds of network tariffs associated with DG. One is connection charge for DG, which is paid by DG producers once when they require network access to compensate for the costs of connection. The other one is use-of-system (UoS) charge, which is paid by DG producers periodically to compensate the operation cost of network and capital expenses for new investment [32]. Who designs the tariffs and how the tariff structure should be designed depend on regulation. In Spain, by regulation the tariffs are sent to a regulatory body, who splits them into different cost categories [33]. In Sweden, the tariffs are designed by DSOs but the total revenue of each DSO is regulated [34]. In the countries where DSOs are motivated to connect DG by regulation, network tariff design should be high enough to recover the DSO's cost, but not too high to dilute the DG connection incentives. The cost for a DSO can be divided into two separate categories: capital expenditures (CAPEX) and operational expenditures (OPEX). An overview of revenue and cost structure of a DSO is shown in Fig 3 [35]. Only costs that are related to DG and can be controlled by the DSO are displayed. Other costs, like taxes and debt costs, are not covered here. Network tariffs will be explained more in Section III-A. After that different tariff designs are compared in Section III-B.

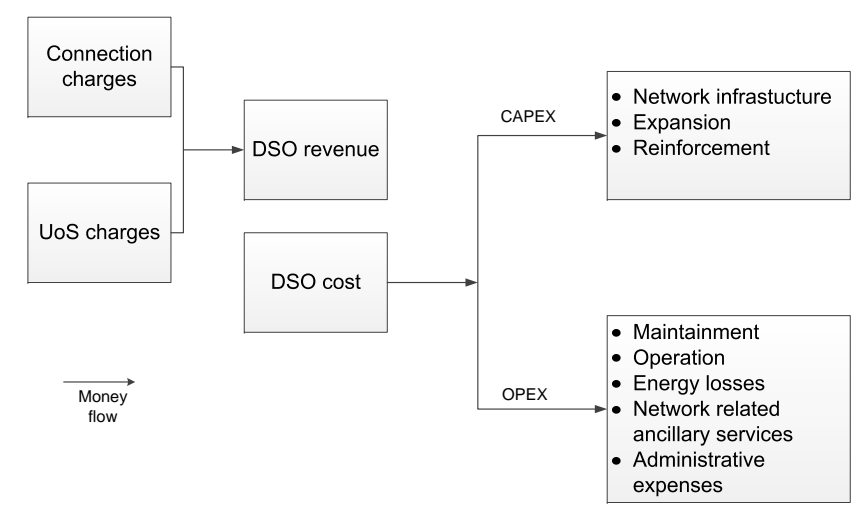

Fig. 3. Revenue and cost of a DSO

\section{A. Different network tariffs}

Connection of generators to the network may have a technical impact on the rest of the network in terms of reliability and stability. To evaluate the reinforcement that may be required at different network levels a system impact study is usually conducted [32]. How the reinforcement cost caused by DG should be recovered depends on regulation. The network tariff is one way to compensate the DSO's cost. Connection charges can be computed from a shallow way to a deep way. Under shallow charging method, only the direct costs of the connection lines from the DG to the nearest bus in distribution network are compensated, while additional costs for network reinforcements and upgrades are socialized among the grid users and paid through the UoS charges [10]. By contrast, under deep charging method all the costs and benefits associated with the connection of a DG, including upstream network reinforcements, are counted. Other charging methods are just mixtures between these two. UoS charges are used to compensate operating and capital expenses incurred to provide the network users with the electricity transport services. A number of cost allocation methods at the transmission level can be found in [32]. In most European countries, DG operators do not pay UoS charges [36]. 
TABLE II

A NETWORK TARIFF COMPARISON OF DIFFERENT COUNTRIES

\begin{tabular}{llll}
\hline DSO & Revenue regulation scheme & Connection charges for DG & UoS charges for DG \\
\hline New England (USA) & Rate-of-return & Deep & Net electricity consumed \\
\hline Queensland (Australia) & Revenue cap & Deep & Net electricity consumed \\
\hline Portugal and Spain & $\begin{array}{l}\text { Hybrid revenue cap and rate-of- } \\
\text { return }\end{array}$ & Deep & No \\
\hline Germany & Revenue cap & Shallow & No \\
\hline United Kingdom & Price cap & Shallowish & Both consumption and generation \\
\hline Italy & $\begin{array}{l}\text { Price cap on OPEX and rate of } \\
\text { return on CAPEX }\end{array}$ & Shallow & Both consumption and generation \\
\hline
\end{tabular}

From an operational point of view, to achieve network efficiency due to the increasing DG, adding location and timing signals to network tariffs promotes the contribution of DG to the network [10]. Many researches have started to develop charging methods to reflect the value of DG. In [37] an efficient network pricing method based on marginal cost pricing principles for UoS charge has been proposed. In [38] a form of location differentiation in deep connection charges is proposed for Germany. In [39] a nodal pricing method to quantify the distribution network UoS charges for either demand or generation is proposed.

How to allocate the costs of transmission facilities fairly and transparently is also a challenge for transmission system operators (TSOs). One widely used approach is the power-flowbased MW-mile method [40]. However, under this method the total costs are not fully recovered since the lines are not used to their capacities. To recover the rest of the costs, the postage stamp approach together with power-flow-based MWmile method is discussed in [40] and [41]. Furthermore, a dynamic point tariff method is discussed in [42]. Under this method the tariff is the difference between nodal price of the node and the market price. The price difference is due to marginal losses if there are no capacity constraints in the system [42]. Hence, under this dynamic point tariff method costs for losses has a potential to decrease. In order to consider not only the use of network and power losses but also the congestion management costs, another method is developed and tested in [43].

\section{B. Comparison of different network tariff structures}

The network tariff structures provided by a number of DSOs from seven different countries are compared in this section. The countries are New England, Queensland, Portugal, Spain, Germany, United Kingdom and Italy. The comparison is based on the publications [32] [33] [44] and [45]. In each case, before exploring the tariff designs in detail, the general electric power system characteristics and main related regulations will be discussed. The result is summarized in Table II.

1) New England (USA): In New England, it is the system operator (it is called independent system operator) who is responsible for calculating the network tariff, but networks are owned by other companies. The revenues of all the network companies are regulated through a rate-of-return mechanism. Network tariffs are clear and transparent. Customers can choose a fixed rate tariff or a time-of-tariff with differentiated charges for peak and off-peak periods. Network tariff structures are similar at the distribution level among different states. Connection charges for DG are deep. Therefore, the capacity and type of DG are affected in order to decrease the connection charges. Prosumers (consumers with DG) are charged in a net-metered manner, in addition to deep connection cost. When prosumers consume more electricity than they generate, they are charged for the net electricity consumed. In addition to that, prosumers receive payments for supplying electricity to the network, which is one way to motivate more DG connection. The payment rate depends on their customer category.

2) Queensland (Australia): Distribution networks in Australia can be government-owned, privately owned or a joint venture. The regulation is different for different DSOs. Ergon Energy is the DSO in Queensland, their tariff design will be used as an example because it is one of the largest distributors in Australia. Ergon Energy is regulated under a revenue cap with a five year review period. The regulated asset base (RAB), which is the financial value of network assets, is determined at the beginning of the review period. Connection charges for DG are deep, which include connection assets and the network reinforcements. These charges are in the form of a fixed daily charge for each day a user is connected to the network over the billing cycle. Apart from paying the deep connection charges, DG producers also pay UoS charges when they act as a load. In addition, they can receive payment when saving DSO's UoS to transmission network in addition to net metered energy payments.

3) Portugal and Spain: Ninety-nine percent of distribution networks in Portugal are owned by one company, therefore it serves the only DSO. The tariffs are established by regulatory body. DG operators pay deep connection charges and do not pay for network use. The high degree of voltage and time of use differentiation allows the access tariffs to reflect the cost of providing network service to individual customers, however, the lack of geographical variation in tariffs fails to allocate costs to various network users. In Spain distribution networks are owned by some large investor owned utilities and a few small companies. The tariff system and revenue regulation are very similar as in Portugal, deep connection charge and no UoS charges for DG. However, the total income for DSO is based on the previous year income modified by 
the national average demand increase, the price index and a certain efficiency factor. Network tariffs collected by DSOs are sent to the regulatory body, who splits them into different cost categories. DSOs will receive the part which is associated to distribution cost. DG producers in Spain receive subsidies by regulation and consequently the costs for end-users increase.

4) Germany: DG production in Germany is increasing very fast, especially generation from renewable energy. A special treatment is defined for renewable energy generators in regulation. However, non-renewable energy generators have to individually negotiate access to the grid with the grid operator. Germany has around 700 DSOs. The German regulator is responsible for regulating and authorizing DSOs, including approving network tariffs. Since 2009 Germany has implemented revenue cap regulation. There is no UoS tariffs for any energy generator, connection charges for generators are shallow. The costs for upgrading and extension are recovered by higher network consumer tariffs. Furthermore, network concessions exist in Germany, for example, wind farms can build their own network for the only purpose of connecting the wind farm to the power system.

5) United Kingdom: United Kingdom has 13 DSOs licensed by the regulator, in addition, there are four independent licensed network operators that own and run networks embedded in the DSOs' network, called independent distribution network operators (IDNO). An alternative arrangement is to build a private network. This private network allows a certain amount of unlicensed generation and allows DG to be connected directly to this network. A private network also has many other exemptions, such as costs related to the Renewable Obligation, the Climate Change Levy, and the Energy Efficiency Commitment. All DSOs are regulated through price-cap regulation. DG developers should pay $80 \%$ of the upgrading costs if the connection requires any distribution network upgrades. The charging methodology can be defined by each DSO but must be approved by the regulator. In addition, DG also must pay UoS charges (£1/kW/year) together with a revenue driver $(£ 1.50 / \mathrm{kW} /$ year) for DSOs which are defined by the regulator. Moreover, the UoS charges and the revenue driver are the same for all DSOs. Thus, DG which does not cause any network upgrades will only be charged the revenue driver, which is set as an incentive for DSOs to connect as much DG as possible in an economic and efficient way. Furthermore, the regulator is pressing the DSOs to develop charging models that reflect the benefits and costs of DG.

6) Italy: Approximately eighty-six percent of the total capacity of distribution network belongs to one DSO, Enel Distribuzione. The revenue regulation is price cap on OPEX and rate of return on CAPEX. The incentives for DG is mainly provided by market based green certificate. DG producers pay shallow connection charges which are negotiated by DSO and DG producers, while the reinforcement in network is socialized by customers. UoS charges that are paid by both generators and end users are initially set by regulation, but there is some leeway for DSO in the application of the UoS charges. DG will receive payment for its production, plus a compensation for network benefits. However, there is no location signal in network tariff.

\section{CASE STUDY}

There are about 170 DSOs in Sweden, and they are under revenue cap regulation since January 2012 [34]. DSOs are not allowed to own generation for selling electricity. DG producers pay deep connection charges and does not pay UoS charges. DSOs can design network tariffs for DG under regulation. A survey will be conducted among Swedish DSOs regarding network planning methods and tariff design. This case study presents some preliminary results from an interview with three DSOs (Fortum, Vattenfall and Ystad) in Sweden. The results mainly focus on four areas described in Section A-D.

\section{A. Questions regarding the investment process}

DSOs perform an individual investment study for each wind farm project. In the study most DSOs use simulation tools for network planning for a certain network topology, the "optimal" solutions are achieved according to a rule of thumb instead of using any optimization tool. Investigations of different network solutions for the connection of DG are often based on the documents AMP ${ }^{1}$ and ASP ${ }^{2}$. In addition, a Life Cycle Cost (LCC) analysis is carried out, where Net Present Value (NPV) analysis includes cost for losses, building, maintenance and so on, etc. A load flow analysis, evaluation of voltage quality and investigation of capacity in the network will also be performed.

\section{B. Questions about the uncertainties for the DSO regarding DG connections}

DSOs invite potential DG developers to joint meetings to discuss issues such as the connection point and connection time. According to what the representatives from the DSOs estimated, nearly $75 \%$ of the wind farms that have applied for connection will not connect in the end. Therefore, DSOs will only plan the connection lines and reinforcement for wind farms which are decided to connect to the grid and it is the wind farm developers who pay the connection costs. Consequently, mainly the DG developers have incentives to decrease the cost for the network connection. Though DSOs only build for DG that will connect, DSOs will choose a flexible solution for future expansion. One new challenge that DSOs have encountered is that the protection system has been activated when a wind farm is producing more than they have specified. Another challenge faced by DSOs with increasing wind power is that the production could exceed the consumption during some periods. The distribution network can transmit the energy to superior network, however, it becomes very expensive for the DSO.

\footnotetext{
${ }^{1}$ AMP stands for Anslutning av mindre produktionsanläggningar till elnätet. It is a handbook for new connection with its main technical impact on local grid in Swedish.

${ }^{2}$ ASP stands for Anslutning av större produktionsanläggningar till elnätet. It is a handbook for new connection with its main technical impact on regional network in Swedish.
} 


\section{Questions regarding the process of connecting DG to the} network

The reliability of the network that starts from the connection point to the wind turbines is decided by the producers. They choose from meshed network or parallel transformers to improve the reliability or turbines that perform better. Moreover, line concession to DG developers is possible, and one DSO can have line concession in another DSO's area. Therefore, DG developers are allowed to build electricity lines between the DG plants and distribution network [46]. As licensing procedures for production plants and electricity networks are not coordinated, an exemption for the network concession requirement is under discussion to speed up processing times [46]. Furthermore, connection of DG to network is not region restricted, DG developers also can connect to neighboring DSOs. Note that DSOs are responsible for the power quality, if the production from DG does not fulfill the quality requirements, the DSO has the permission to disconnect the DG.

\section{Questions regarding the network tariff for the DG}

DG producers need to pay deep connection charge that includes the reinforcement caused by the generation at distribution level and transmission level. The amount of connection fee implies the preference by DSOs, however, DSOs are not actively sending out signals of preference for DG connection nodes. DSOs recover all the cost through network tariff, although it is yet not clear how to separate the reinforcement cost. In addition, channel tariffs are used to send out incentives for some nodes in regional network. Latest Swedish regulation was issued in January 2012, but there is no indication from DSOs that network tariff structure for DG would affect. It is agreed that the network revenue regulation has no impact on the tariff design for the DG so far.

\section{CONClusion}

Integration of distributed generation (DG) increases the challenges for distribution system operators (DSOs). Two challenges that are related to DSOs' incomes are reviewed in this paper: one is network planning with DG which is related to DSOs' costs and the other is network tariff designs for DG which is related to DSOs' revenues. The paper also presents preliminary results from a study of the situation for Swedish DSOs with DG.

Firstly, results from the review show that network planning methods for DSOs that can decide the location and size of DG are well developed. However, deregulation of electric power business has led to unbundling of production and network operation. In many countries DSOs are not allowed to own power production. Therefore, the location and size of DG will not be decided by the DSO and thus become uncertain factors in the network planning process. Only a few publications that formulate the network planning problem in such a way have been found in the review.

Secondly, results from the review show that the network regulation has little impact on the DSO's design of network tariff for the DG. Most of the network tariffs do not express the value of DG for the network. The case study of Swedish DSOs confirms the results from the review that network planning methods used nowadays are still suitable for systems with a small share of DG. Incentives to DG producers given by the DSO through tariffs to connect to certain points in the network only exist for regional networks in Sweden.

With increasing penetration of DG it is important to develop better network planning methods and more efficient network tariff charging methods for DG. In order to build future work on the correct understanding of challenges in nowadays situation and possible future scenarios, surveys among DSOs, DG developers and transmission system operator (TSO) will be conducted.

\section{REFERENCES}

[1] T. Ackermann, A. Göran, and L. Söder, "Distributed generation: a definition," Electric Power Systems Research, vol. 57, no. 3, pp. 195-204, Apr. 2001.

[2] G. Pepermans, J. Driesen, D. Haeseldonckx, R. Belmans, and W. D'haeseleer, "Distributed generation: definition, benefits and issues," Energy Policy, vol. 33, no. 6, pp. 787-798, Apr. 2005.

[3] L. F. Ochoa, A. Padilha-Feltrin, and G. P. Harrison, "Evaluating distributed generation impacts with a multiobjective index," Power Delivery, IEEE Transactions on, vol. 21, no. 3, pp. 1452-1458, Jul. 2006.

[4] J. Lopes, N. Hatziargyriou, J. Mutale, P. Djapic, and N. Jenkins, "Integrating distributed generation into electric power systems: A review of drivers, challenges and opportunities," Electric Power Systems Research, vol. 77, no. 9, pp. 1189-1203, Jul. 2007.

[5] D. Trebolle, T. Gómez, R. Cossent, and P. Frías, "Distribution planning with reliability options for distributed generation," Electric Power Systems Research, vol. 80, no. 2, pp. 222-229, Feb. 2010.

[6] G. P. Harrison and A. R. Wallace, "Optimal power flow evaluation of distribution network capacity for the connection of distributed generation," Generation, Transmission and Distribution, IEE Proceedings-, vol. 152, no. 1, pp. 115-122, Jan. 2005.

[7] A. Alarcon-Rodriguez, G. Ault, and S. Galloway, "Multi-objective planning of distributed energy resources: A review of the state-of-theart," Renewable and Sustainable Energy Reviews, vol. 14, no. 5, pp. 1353-1366, Jun. 2010.

[8] X. Tao and H. J. Haubrich, "A Two-Stage Heuristic Method for the Planning of Medium Voltage Distribution Networks with Large-Scale Distributed Generation," in Probabilistic Methods Applied to Power Systems, 2006. PMAPS 2006. International Conference on. IEEE, Jun. 2006, pp. 1-6.

[9] A. Orths, A. Bachry, C. Böse, O. Ruhle, and Z. Styczynski, "Dispersed Generation in Distribution Networks: Performance Simulation Based on New Planning Technique's Results-Case Study," in 17th International Conference on Electricity Distribution CIRED, Barcelona, Spain, 2003.

[10] P. Frías, T. Gómez, R. Cossent, and J. Rivier, "Improvements in current European network regulation to facilitate the integration of distributed generation," International Journal of Electrical Power \& Energy Systems, vol. 31, no. 9, pp. 445-451, Oct. 2009.

[11] D. Pudjianto, G. Strbac, and J. Mutale, "Access and Pricing of Distribution Network with Distributed Generation," in Power Engineering Society General Meeting, 2007. IEEE. IEEE, Jun. 2007, pp. 1-3.

[12] C. Christophe and K. George, "Agent-Based Modeliing \& Simulation applied to the Planning of Distribution Systems," BP 207 F-06904 Sophia Antipolis Cedex France, Tech. Rep., Dec. 2009.

[13] V. Neimane, "On development planning of electricity distribution networks," Doctoral phd thesis, Royal Institute of Technology Stockholm, 2001.

[14] G. Celli and F. Pilo, "MV network planning under uncertainties on distributed generation penetration," in Power Engineering Society Summer Meeting, 2001, vol. 1. IEEE, 2001, pp. 485-490 vol.1.

[15] E. G. Carrano, F. G. Guimaraes, R. H. C. Takahashi, O. M. Neto, and F. Campelo, "Electric Distribution Network Expansion Under Load-Evolution Uncertainty Using an Immune System Inspired Algorithm," Power Systems, IEEE Transactions on, vol. 22, no. 2, pp. 851-861, May 2007.

[16] R. Ranjan, "A new algorithm for power distribution system planning," Electric Power Systems Research, vol. 62, no. 1, pp. 55-65, May 2002. 
[17] I. J. Ramirez-Rosado and J. A. Dominguez-Navarro, "New multiobjective tabu search algorithm for fuzzy optimal planning of power distribution systems," Power Systems, IEEE Transactions on, vol. 21, no. 1, pp. 224-233, Feb. 2006.

[18] S. Ganguly, N. C. Sahoo, and D. Das, "Mono- and multi-objective planning of electrical distribution networks using particle swarm optimization," Applied Soft Computing, vol. 11, no. 2, pp. 2391-2405, Mar. 2011.

[19] M. S. Kandil, S. M. El-Debeiky, and N. E. Hasanien, "Long-term load forecasting for fast developing utility using a knowledge-based expert system," Power Systems, IEEE Transactions on, vol. 17, no. 2, pp. 491-496, May 2002.

[20] E. L. Da Silva, J. M. A. Ortiz, G. C. De Oliveira, and S. Binato, "Transmission network expansion planning under a Tabu Search approach," Power Systems, IEEE Transactions on, vol. 16, no. 1, pp. 62-68, Feb. 2001.

[21] L. S. Rezende, A. M. Leite da Silva, and L. Mello Honório, "Artificial Immune System Applied to the Multi-stage Transmission Expansion Planning Artificial Immune Systems," ser. Lecture Notes in Computer Science, P. S. Andrews, J. Timmis, N. D. L. Owens, U. Aickelin, E. Hart, A. Hone, and A. M. Tyrrell, Eds. Berlin, Heidelberg: Springer Berlin / Heidelberg, 2009, vol. 5666, ch. 19, pp. 178-191.

[22] Y.-X. Jin, H.-Z. Cheng, J.-y. Yan, and L. Zhang, "New discrete method for particle swarm optimization and its application in transmission network expansion planning," Electric Power Systems Research, vol. 77, no. 3-4, pp. 227-233, Mar. 2007.

[23] M. R. Hesamzadeh, "Transmission planning in liberalised electricity markets in the context of market power," Ph.D. dissertation, 2010.

[24] I. J. Ramirez-Rosado and J. A. Dominguez-Navarro, "Possibilistic model based on fuzzy sets for the multiobjective optimal planning of electric power distribution networks," Power Systems, IEEE Transactions on, vol. 19, no. 4, pp. 1801-1810, Nov. 2004.

[25] L. N. D. Castro and J. I. Timmis, "Artificial immune systems as a novel soft computing paradigm," Soft Computing-A Fusion of Foundations, Methodologies and Applications, vol. 7, no. 8, pp. 526-544, 2003.

[26] P. S. Sensarma, M. Rahmani, and A. Carvalho, "A comprehensive method for optimal expansion planning using particle swarm optimization," in Power Engineering Society Winter Meeting, 2002. IEEE, vol. 2. IEEE, 2002, pp. 1317-1322 vol.2.

[27] A. Orths, A. Schmitt, Z. A. Styczynski, and J. Verstege, "Multi-criteria optimization methods for planning and operation of electrical energy systems," Electrical Engineering (Archiv fur Elektrotechnik), vol. 83, no. 5, pp. 251-258, Nov. 2001.

[28] G. J. Anders, Probability concepts in electric power systems. New York, NY; John Wiley and Sons Inc., Jan. 1989.

[29] V. Miranda and L. M. Proenca, "Probabilistic choice vs. risk analysis-conflicts and synthesis in power system planning," in Power Industry Computer Applications., 1997. 20th International Conference on. IEEE, May 1997, pp. 16-21.

[30] P. Caramia, G. Carpinelli, A. Russo, and P. Verde, "Decision theory criteria for medium voltage cable sizing in presence of nonlinear loads," International Journal of Electrical Power \& Energy Systems, vol. 23, no. 7, pp. 507-516, Oct. 2001.

[31] V. Miranda and L. M. Proenca, "Why risk analysis outperforms probabilistic choice as the effective decision support paradigm for power system planning," Power Systems, IEEE Transactions on, vol. 13, no. 2, pp. 643-648, May 1998

[32] V. Sakhrani and J. E. Parsons, "Electricity Network Tariff Architectures A Comparison of Four OECD Countries," Social Science Research Network Working Paper Series, Nov. 2010.

[33] L. Söder, A. Atterwall, and S. Persson, "Grid issues for Electricity Production Based on Renewable Energy Sources in Spain, Portugal, Germany, and United Kingdom," Statens offentliga utredningar, Tech. Rep., 2008.

[34] M. Bollen, "Adapting Electricity Networks to a Sustainable Energy System," Energy Markets Inspectorate, Tech. Rep., 2011.

[35] J. de Joode, J. C. Jansen, A. J. van der Welle, and M. J. J. Scheepers, "Increasing penetration of renewable and distributed electricity generation and the need for different network regulation," Energy Policy, vol. 37, no. 8, pp. 2907-2915, Aug. 2009.

[36] Y. Huang and H. Olsson, "Market concepts and regulatory bottlenecks for smart distribution grids in EU countries," 2011.

[37] G. Strbac, J. Mutale, and D. Pudjianto, "Pricing of distribution networks with distributed generation," in Future Power Systems, 2005

International Conference on. IEEE, Nov. 2005, pp. 6 pp.-6.
[38] C. Brandstatt, G. Brunekreeft, and N. Friedrichsen, "Locational distribution network pricing in Germany," in Power and Energy Society General Meeting, 2011 IEEE. IEEE, Jul. 2011, pp. 1-3.

[39] C. T. Mancera and A. C. Monroy, "Pricing of distribution networks with distributed generation: Application of nodal pricing," in Innovative Smart Grid Technologies (ISGT Latin America), 2011 IEEE PES Conference on. IEEE, Oct. 2011, pp. 1-7.

[40] M. Z. Meah, A. Mohamed, and S. Serwan, "Comparative analysis of using MW-Mile methods in transmission cost allocation for the Malaysia power system," in Power Engineering Conference, 2003. PECon 2003. Proceedings. National. IEEE, Dec. 2003, pp. 379-382.

[41] B. Kharbas, M. Fozdar, and H. Tiwari, "Transmission tariff allocation using combined MW-Mile \& Postage stamp methods," in Innovative Smart Grid Technologies - India (ISGT India), 2011 IEEE PES. IEEE, Dec. 2011, pp. 6-11.

[42] G. Warland, O. B. Fosso, I. Wangensteen, and O. Wolfgang, "Efficient transmission pricing in power systems with considerable time-dependency," in Power Engineering Conference, 2005. IPEC 2005. The 7th International. IEEE, Nov. 2005, pp. 1-438.

[43] J. Ferreira, Z. Vale, T. Sousa, B. Canizes, and J. Puga, "Transmission costs allocation based on optimal re-dispatch," in Energy Market (EEM), 2011 8th International Conference on the European. IEEE, May 2011, pp. 473-478.

[44] N. Boccard, "A benchmarking of 9 European member states policies towards distributed generation," SUSTELNET Report, University of Girona, 2004

[45] N. Committee, "Regulation for smart grids," Eurelectric, Tech. Rep., Feb. 2011.

[46] L. Söder, A. Atterwall, and S. Persson, "Bättre kontakt via nätet : om anslutning av förnybar elproduktion," (Batter contact online : The connection of renewable generation), Available in Swedish, Tech. Rep., 2008 .

Yalin Huang was born in Hubei, China in 1987. She received her B.Sc. degree in Electrical Engineering from South China University of Technology, China, in 2009. She received his M.Sc. degree in Electrical Engineering from Royal Institute of Technology (KTH) in 2011. She starts her PhD research in 2011. Her research topic is risk analysis methods and network regulation for electric power systems with integrated distributed generation.

Karin Alvehag (M'11) was born in Stockholm, Sweden in 1981. She received her Ph.D. in Electrical Engineering from the KTH Royal Institute of Technology, Stockholm, Sweden in 2011. She holds a M.Sc. degree in Engineering Physics from KTH. Her research topics are distributed generation, distribution system reliability, risk analysis, quality regulation and customer interruption cost assessments.

Lennart Söder (M'91) was born in Solna, Sweden in 1956. He received his M.Sc. and Ph.D. degrees in Electrical Engineering from the KTH Royal Institute of Technology, Stockholm, Sweden in 1982 and 1988, respectively. $\mathrm{He}$ is currently a professor in Electric Power Systems at the Royal Institute of Technology (KTH). He also works with projects concerning deregulated electricity markets and integration of wind power. 